\title{
Conference report: Doctors in performance, Tallinn, 1-3 September 2021
}

\section{$3^{\text {I }}{ }^{\text {ST }}$ August 202 I}

I head towards the harbour in Jätkäsaari to board a ferry from Helsinki to Tallinn. It is my first trip to a place outside of Finland in thirteen months. I understand that most of the participants who have decided to go to Tallinn for the conference will be experiencing their first trip for a long while as well. As part of the new regulations for travel abroad, we have all acquired a Covid certificate in advance of travel. It is a beautiful day with a clear sky. The temperature is about 19c, and although it feels very warm in the sun, there are clear signs that autumn is under way. It is strange to be travelling again.

Doctors in Performance (DiP) is a biennial series of conferences, founded and first hosted in 2014 by the Sibelius Academy of Music, University of the Arts Helsinki. The official name of the conference is "Doctors in Performance: Festival Conference of Music Performance and Artistic Research". Following the Helsinki inauguration in 2014, it has travelled to the Royal Irish Academy of Music (2016) and the Lithuanian Academy of Music and Theatre (2018). The Estonian Academy of Music and Theatre has been appointed as the host of the 2020 session. Postponed by a year due to the pandemic, the 2021 session is the fourth in the series.

As the title suggests, the conference puts equal emphasis on music performance and artistic research. This is an original feature of this conference series. In Europe, the Society of Artistic Research (SAR) conference series emphasises artistic research and embraces all artistic disciplines, of which music, and particularly classical music, tends to be a small part. The European Platform for Artistic Research in Music (EPARM) conference series focuses on artistic research conducted in music, the remit of which frequently goes beyond music performance. $\mathrm{DiP}$ is distinct in the way in which it selects participants: for all proposals that include performance, it asks for an audio-visual recording to be submitted with the proposal. For DiP, the quality of performance as research matters.

The fourth Festival Conference takes place at the Estonian Academy of Music and Theatre (EAMT), led by Kristel Pappel, Head of the Centre for Doctoral Studies and its Organizing Committee. The conference programme and abstracts are published in advance and includes 46 presentations in total, including two keynotes. 
There are thirty in-person presentations (including two keynotes) and 16 online presentations. It takes a "hybrid" format, which is becoming the standard at all conferences, festivals, and a whole range of activities including teaching; all will be live-streamed. I am curious about what kinds of hybridity this DiP adopts and what kind of effect it creates amongst the participants (both in-person and online). For my part, this is the first hybrid event at which I participate in person, and I plan to reflect later on the merits and otherwise of different hybrid formats that I have experienced in 2020-21.

In terms of presentation types, there are 18 papers, 10 recitals, and 16 lecturerecitals out of the 44 presentations (excluding keynotes). This is not an exact distribution because the last-minute changes of circumstances - such as travel arrangements and safe distance rules - may affect the exact content when deciding between in-person or online but also the question of recorded or live performance. Still, it is worthwhile to observe that the majority of presentations involves some performance actions.

On arrival by ferry in Estonia, we queue for a Covid certificate check at the border control, which goes relatively smoothly. The Conference Organisation Committee has informed us in advance that in Estonia the ID and Covid certificate will be required to enter any public space, including restaurants and concert halls. The fact that rules vary from one EU country to another is part of the adventure we are about to experience.

The Organising Committee has emailed the participants a $\mathrm{QR}$ code in advance for free public transport in Tallinn for the duration of the conference. This is one of the several signs which speak for the organisational excellence of this committee.

\section{$1^{\text {st }}$ September 2021}

The conference begins at 9:30 am. I register myself earlier in the morning in the foyer of the concert hall. This wing of the campus is new, finished in 2019, a mere couple of months before the pandemic started. The Festival Conference is presented in a beautifully produced, concise, ring-bound and easy-to-reference A5 booklet containing a clear timetable as well as well-presented and well-proofread abstracts and biographies. Each participant is introduced with a photo, which helps with identifying them in person. The Festival Conference bag includes a double CD set of music performances recorded in the new concert hall between September 2019 and April 2021.

The new concert hall is beautiful and impressive. The 480-capacity hall has a box shape and feels larger because of its high ceiling. Wood is featured in all directions with the finest acoustics in Estonia. I can imagine how this space lifts the morale of staff and students alike. It also lifts the morale of visitors such as the conference participants. The Estonian Academy has not yet experienced a full season in this concert hall, and this conference is one of the first international events to introduce this fantastic hall to the world. 
The morning starts with three sessions in the three halls of EAMT: the Great Hall (the concert hall), Chamber Hall (high ceiling space with flexible floor seating with theatre-style movable lighting), and Organ Hall (with quite a large organ for the room size). The three venues host three types of presentations: papers are held in the Organ Hall, recitals in the Great Hall, and lecture recitals in the Chamber Hall. Papers are assigned 30 minutes each and recitals and lecture-recitals 60 minutes each, including a discussion period. All the sessions are held live (following a very strict timetable) and live-streamed. The chair of each session manages both in-person interactions and online Q\&A by reading out questions to the presenter. The technical set-up is impressive with three technicians in each venue (two in front of the computers and one handling the camera). In addition, there is an assistant in charge of handing a microphone for live audience questions and comments. Clearly, EAMT has thought of everything. There is even a corner in the foyer where you can test your equipment for a presentation. The most impressive is the calm with which the EAMT staff handle this "new normal".

I go to the Chamber Hall for the morning to attend two lecture recitals. The first presenter, Justyna Jablonska, was scheduled to arrive from Edinburgh but has not been able to travel and instead opts to give her presentation online. Her topic is about an adaptation for the cello of the Carnatic Gamaka, a particular type of Indian music with improvisation. Given the circumstance of having to deliver a presentation from a distance, she has made the intelligent choice to record her presentation in advance (which included an artistically produced performance) and plays this video of approximately 40 minutes with a live online introduction beforehand and a live discussion afterwards.

We are facing the "new normal" scenario right from the onset. We gather in one space, look at the large screen together on which a video is played, and talk with the presenter afterwards live on the screen. The presenter has an overview of the audience, aware of their approximate size, but I don't think she can feel the atmosphere. The chair (Giovanni Albini) is tasked with keeping the discussion going across the in-person audience, online audience, and the presenter. Jablonska's presentation shows honesty and clarity of thought, and she is very personable. Yet, I am left wondering who her "audience" is. Does she assume that her listeners are like herself, classically trained musicians venturing into "another" music? Knowing that the people in the Chamber Hall are only one part of the audience, it is not certain who are "you" or "we" in the discourse. Of course, this is not a criticism of the presentation itself. Rather, the thoughtfully chosen but unique format of the presentation simply raises issues that we have not encountered before.

The second presentation at 10:30 am is with an in-person presenter, Lore Amenabar Larranaga, with her quartertone accordion. Her mission is to create a repertoire for this bespoke instrument, and her presentation is packed with useful information for composers as well as playing some examples on this instrument. It is 
fascinating to observe how she handles the resonance and musical line. Her playing tells eloquently how her knowledge and skill in playing the standard (twelve-tone) accordion is transferred to this new instrument.

Prior to the Opening session in the Great Hall at 12:00 pm, there is a coffee break in the foyers. It is one of the moments of warmth and empathy that we have been longing for. We see smiles, chats and laughter, things that may not be essential but are still good to have, all around. How good coffee tastes in good company!

The plenary Opening session is held in the Great Hall. The Opening welcome and speech are given by the representatives of the groups who have made this conference possible: Kristel Pappel as the representative of the Organising Committee at EAMT; Rector Ivari Ilja of EAMT; Anu Vehviläinen of Sibelius Academy, representing the DiP Steering Committee; and Hanneleen Pihlak, in charge of all practical matters from the Organising Committee. There is a quiet sense of marvel and euphoria in having managed to meet and hold the session in this manner. Collective gratitude and appreciation go to these groups of people for having thrived through challenging times and brought about this conference in September 2021, with the pandemic still far from over.

The first keynote presentation by cellist Neil Heyde of the Royal Academy of Music, London follows the Opening without a break. In "Dialogues with Recordings: Digital Memory and the Archive", Heyde explores the significance of old recordings as a collective memory in the composition, performance, perception, and enjoyment of music today. He presents a recorded performance of himself playing a piece (new work by Richard Beaudoin), the aesthetic content of which makes a strong reference to the old recording of Bach D minor Suite by Casals. The complex effect of recorded media on the performer and listener is the focus of the argument. Heyde elucidates the resulting "dialogue" that arises from the interaction with Casals's Bach and how this interaction becomes an integral part of the piece. He makes a reference to Marshall McLuhan's The Medium is the Message (1964), which has been going through a revival in recent years in the use of social media. What I find particularly interesting about Heyde's presentations (as well as others elsewhere) is his awareness of contemporary sensibilities. This is not necessarily because he talks about new music: he sees how aesthetics, music perception and performance are intertwined and constantly changing, whichever music we engage with.

There are two more sets of parallel sessions in the afternoon. I go to the session with online papers (Olga Heikkilä, Phoebe Robertson, Lorelei Dowling, Charles Quevillon, chaired by Sten Lassmann and Jaak Sikk) in the Organ Hall. One of the papers is a pre-recorded video presentation, and the others are live but remote. The topics are fascinating and show a wide range of subjects being researched today: voice embodiment, music theatre as ritual, the promotion of a lesser-known instrument, and others, all approached in and through a practice of music performance. 
While the content is enlightening, I am again sensing different ideas of "audience" in these new hybrid formats.

There is a concert at $6 \mathrm{pm}$ given by musicians carrying out doctoral studies at EAMT. A diverse range of compositions and ensembles is presented. The performances are well rehearsed and well executed; the concert is curated to flow from one piece to the next and the gaps are bridged by small interludes on non-pitched percussion instruments (thus creating contrast to the pitched instruments on stage) performed on the front balcony. The concert is directed with spectacular lighting effects, which responds vividly to the live sound. This is a celebration of the talents as well as the state-of-the-art technology of this concert hall.

\section{$2^{\mathrm{ND}}$ SePtember $202 \mathrm{I}$}

I go to the Recital session (Kirill Kozlovski, Kristi Kapten, chaired by Anu Vehviläinen) in the Great Hall starting at 9:30 am. Both presenters are pianists, and it is an opportunity to listen to live performances on the concert grand piano in a large concert hall, something that I have missed for a long time. While the Recital presentation has a more substantial performance component than the Lecture Recital, the precise balance and mix of speech and playing are at the discretion of the presenter according to the content. Kozlovski gives a recital prefaced by an introduction, and Kapten intersperses her playing with explanations, using one to support the other, while Kozlovski makes a point of letting his playing do the talking. There is a clarity of vision, and his playing expresses his thought more than any words could.

The next session after a coffee break is the second keynote presentation, by Allan Vurma of EAMT, who has served the national and international music communities as singer, teacher and researcher for many years. In "Crossover Between Singing and Science", Vurma presents his career-long research on voice and acoustics by reviewing two projects that he has carried out. The explanations are clear and exemplary, accompanied by appropriate audio and animated materials. While his methodology can be seen as more "scientific" than artistic, his artistic knowledge and experience is amply revealed in his responses to questions and comments after his presentation. He is very much aware of the complex relationship between science and art, and I appreciate the care he takes in avoiding easy answers. His responses reflect the depth and breadth of his thought and musicality.

One of the features of this conference is a 90-minute lunch break, which sets a comfortable tempo to the proceedings. Even though there is a three-hour set of parallel sessions in the afternoon, in which a total of eleven presentations (5 papers, 3 lecture-recitals and 3 recitals) take place, I don't feel overwhelmed by the wave of people and information, which we often experience at conferences. The Conference Dinner follows in the evening at the rooftop garden restaurant of Fo- 
tografiska, a fine-art photography centre, some half-hour walk from the Academy. This is the only time it rains during the conference, and we are unfortunate in not being able to venture into the rooftop garden space, which provides a panoramic view of the Tallinn city centre. The conversations are convivial: some thoughtful exchange, light-hearted banter and laughter. Group conversations are much cherished by all. The rain falls only while we are at the table, and many of us enjoy a fine stroll afterwards.

\section{$3^{\mathrm{RD}}$ SePtember $202 \mathrm{I}$}

The weather has moved on to an autumn day with chilly winds, with a day-time temperature of $12 \mathrm{C}$. We are glad to stay indoors. Today I want to see for myself what it is like to participate remotely in the conference where there are on-site participants and audience. After the first session in the morning, I hurriedly return to the hotel room, and my online participation begins via Zoom webinar. Perhaps as expected, I become acutely aware of not being there in person, and I feel a strong sense of being a bystander, much more than at webinars that I have participated in recently prior to this conference. I see that there is a "real" conference going on, with a real community, and I am observing the on-site proceedings from the outside (though I can participate in the Q\&A session by posting questions or comments). There is to my mind a clear distinction between the online conference and the hybrid conference of this type: in the former, everyone is an onlooker with the same distance to the community, while the latter produces on-site and online groups. The distinction amounts to more than the question of coffee being provided at breaks.

We assemble for the last time in the Great Hall for Closing Remarks and Discussion by the Steering Committee at 13:00. Anu Vehviläinen (Sibelius Academy), Sarah Callis (Royal Academy of Music, London), Lina Navickaité-Martinelli (Lithuanian Academy of Music and Theatre) and Markus Kuikka (Sibelius Academy) are on stage. They first voice appreciation for the superb work and effort of the EAMT Organising Committee. They then reflect on the proceedings this year and list identity, pandemic, communication with audience, instruments, and technology as the most frequently mentioned topics in 2021 . They also observe the widening variety of subjects, some interdisciplinary topics and perspectives. They all recognise the value of "meetings", meetings of ideas and personal communication. The discussion includes the question of a future format for DiP. While everyone recognises the benefit of making proceedings accessible online, there is a reminder of the value of in-person meetings as we have all experienced in the last few days.

In the afternoon there is a trip to the Arvo Pärt Centre, about an hour's bus ride away from Tallinn in the middle of a beautiful forest. The Centre was established in 2010 as a foundation, and the building opened in 2018. We feel the vision of the 
composer, what is important to him, and how he, his family and friends, and Estonia more broadly see his artistic legacy. Conversations outside the conference venue expand to faraway topics too, and we bid each other farewell.

\section{$4^{\mathrm{TH}}$ SePtember $202 \mathrm{I}$}

I head to Tallinn's harbour to board a return ferry to Helsinki. By this point I am used to showing my Covid certificate and ID to anyone who looks at me with a particular kind of curiosity. I reflect on the conference onboard. There is a strong sense of a community of artistic research in the Nordic and Baltic countries, and it is spreading over to the United Kingdom. The next $\mathrm{DiP}$ is scheduled for 2023 in London, and hopefully this sense of community will continue and expand.

I return, for the last time, to the question of hybrid formats. While I agree with the idea of making proceedings accessible online, I am not sure about the possible consequences of such a policy on conference organisations. In one of the parallel sessions during the conference, where there were about 15 participants besides the presenter, chair, and technical staff, I asked one of the technical staff afterwards about the number of online participants. The answer was 7-10. With fewer than 25 participants in a group requiring 4 technical staff members (two in front of the computers, one in front of the camera, one with a mobile microphone), how can we sustain it financially in the future? Which solutions might we find?

Online conferences vary in format. As we have also seen in this conference, a pre-recorded video presentation has become a popular format. This has a tendency to encourage a passive, TV-viewing attitude, which is not necessarily a design of the presenter but a habit many of us have accumulated over a lifetime. I have heard the counterargument that a pre-recorded video presentation can be understood as the audio-video modern-day equivalent of reading a paper. On the one hand, TENOR (International Conference on Technologies for Music Notation and Representation), another conference series with many practical demonstrations and performances, was held online in May 2021 (hosted by Hochschule für Musik und Theater, Hamburg) with guidelines insisting on live remote presentations and inclusion of all audio-visual examples into a slide series (with no links). On the other hand, CARPA (Colloquium on Artistic Research in Performing Arts, hosted by Uniarts Helsinki), which was held in August 2021, requested that presenters provide links to examples on platforms such as YouTube or Vimeo in the chat to minimise the loss of audio-visual quality. As with most conferences and discussions, there is also confusion about when to use chat or Q\&A on the Zoom webinar platform.

Finally, as the Helsinki archipelago begins to come into view, I realise that DiP is not only about artistic research and music performance, but also about doctoral education in and around these subject areas. Most presenters have been those who 
TRIO vsk. 10 nro 2 - Raportit: Mieko Kanno 41-48

are currently in or recently completed their doctoral education. Some colleagues who have been involved in DiP since 2014 mention that there has been a general rise in quality and competence in the presentations. $\mathrm{DiP}$ is perhaps unique in this way, that it promotes integration of research into musicians' lifelong education and encourages its sharing. 